\title{
In vitro Evaluation of Accuracy of Single Dies Captured by Two Intraoral Digital Scanners
}

\begin{abstract}
ALEXANDRU VICTOR BURDE ${ }^{1}$, CRISTINA GASPARIK ${ }^{1}$, MARIOARA MOLDOVAN ${ }^{2}$, SORANA BACIU ${ }^{1 *}$, COSMIN COSMA ${ }^{3}$
${ }^{1}$ Iuliu Hatieganu University of Medicine and Pharmacy, Department of Dental Propaedeutics and Esthetics, 32 Clinicilor Str., 400006, Cluj Napoca, Romania

²Babes Bolyai University, Raluca Ripan Chemistry Research Institute, Department of Polymer Composites, 30 Fantanele Str., 400294, Cluj Napoca, Romania

${ }^{3}$ Technical University of Cluj Napoca, Faculty of Materials and Environment Engineering, 103-105 Muncii Blvd., 400641, Cluj Napoca, Romania

The objective of this in-vitro study was to compare the accuracy, defined as trueness and precision, of two intraoral digital scanners that use differentcapturing techniques. An experimental reference objectconsisting of a die was manufactured from a PMMA resin. The reference object was digitized with an industrial CT and was scanned 15 times with each scanner. In order to asses trueness, comparisons were made with the virtual reference model, and for fidelity, the first scan in the series was compared with the following scans. For both fidelity and trueness, the $F$ test and $T$ tests demonstrate that there is a statistically significant difference between the scanners.
\end{abstract}

Keywords: accuracy, precision, trueness, CAD/CAM, CT

Long-term storage of dental models, although required by law and practice guidelines in many countries [1], may become problematic and inconvenient for dental healthcare practitioners [2] for a number of reasons: from the low tensile strength of the gypsum [3], which is liable to cause fractures in plaster models, to the reduced abrasion resistance of the gypsum [4], as well as to the space requirements for storing plaster models [5].

A viable alternative is to digitalize the plaster models and store them in a virtual environment, as well as obtain physical copies of these models through rapid prototyping systems if needed [6-8].

First and foremost, in order to assimilate the use of this technology into everyday practice, the virtual model of the patient must be obtained. This can be done either by directly digitizing the dental arches using optoelectronic intraoral scanners or by digitizing the conventional plaster models using indirect, laboratory scanners [9].

The concept of direct scanning was initiated in 1972 by Professor Francois Duret [10] and the first commercially available scanner was introduced in 1987 by Werner Mormann and Marco Bradestini [11]. Even though, in the early stages of development, this system was used to scan the prepared tooth and its neighboring teeth [9], intraoral scanning gradually evolved and allowed the digitization of a wider area, enabling the scanning of a complete arch, either by making available a series of images or by capturing video footage of the oral area of interest [12].

Nowadays, there are a multitude of manufacturers that produce intraoral scanners [13], which are largely based on 4 main optical scanning technologies: Confocal Laser Scanner Microscopy (CLSM), Optical triangulation, Accordion Fringe Interferometry (AFI) and Active Wavefront Sampling (AWS). However, aside from the technology used by a digital scanner, in order to generate a virtual model that is adequate for use in CAD/CAM reconstructions, increased scanning accuracy is required [14].

Accuracy is described by the ISO standard 5725-1 through the use of two parameters: truenessand precision. Trueness refers to the deviation between the actual dimension of the measured object and the resulting measurement, while precision indicates how closely repeated the measurements in a set are. Currently, several studies focused on the accuracy of intraoral scanners reveal contradictory results [15-20]. Although such studies report a higher degree of accuracy in the case of certain scanning technologies[20-21], the findings of these studies are difficult to contrast and summaries because there is no standard protocol for the performed comparisons.

The aim of this study was to highlight and compare the accuracy (trueness and precision) of two intraoral scanners which use different acquisition technologies, by using a simple reference model and industrial CT in order to perform the evaluation.

\section{Experimental part \\ Materials and method}

In this study, we decided to compare the accuracy of single dies captured by two intraoral scanners that use two differentacquisition technologies: 1) Apollo DI (Sirona Gmbh, Bad Sackingen, Germany) which is based on the principle of continuous video filming with pulsating blue light projection, and 2) DWIO (Dental Wings, Montreal, Canada) which uses a capture technique called Multiscan Imaging with a continuous blue light projection.

In order to perform the current in vitro study, a methodology based on the testing conditions specified in ISO standard 12836:2015 was conceived. For this purpose, three key elements are necessary in order to perform the comparison between the included scanners: a) a reference object, b) a reference digital scanner with a specified accuracy and c) a digital comparison method.

\section{Reference object}

An experimental object in the form of a stump was manufactured by using an ANA 4-Z (Frasaco Gmbh, Tettnang, Germany) model of a permanent maxillary right first molar, which was prepared for a porcelain fused to metal crown by applying the following preparation principles: $1.5 \mathrm{~mm}$ axial and proximal surface reduction, $6^{\circ}$ occlusal convergence, $2 \mathrm{~mm}$ occlusal reduction, 0.8 
$\mathrm{mm}$ rounded chamfer margin. Subsequent to the preparation procedure, the stump was scanned using a 7Series (Dental Wings, Montreal, Canada) structured light scanner. The resulting point cloud file was optimized for CNC milling using the Meshmixer (Autodesk Inc., San Rafael, USA) software and the milling strategy was created using Sum3D (CIMsystem, Cinisello Balsamo, Italy) CAM software.

The stump was milled out of CopraTemp (Whitepeaks Dental Solutions $\mathrm{GmbH}$., Wesel, Germany) tooth-colored poly-methyl-methacrylate disk using a D5 (Datron AG, Mühltal, Germany) CNC milling machine. This material was chosen because of its optical properties, which mimic the hue, saturation and translucency of tooth structures, without including an excess of brightness, which would interfere with structured light scanning. Figure $1 \mathrm{~A}$ shows the milled PMMA stump and figure $1 \mathrm{~B}$ the preparation parameters.

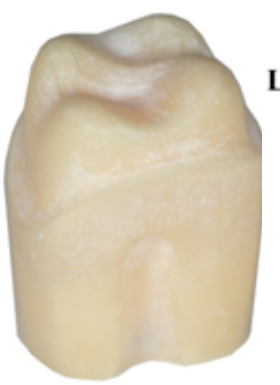

A

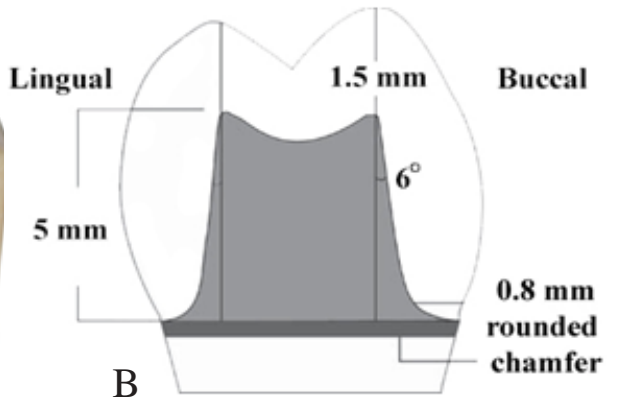

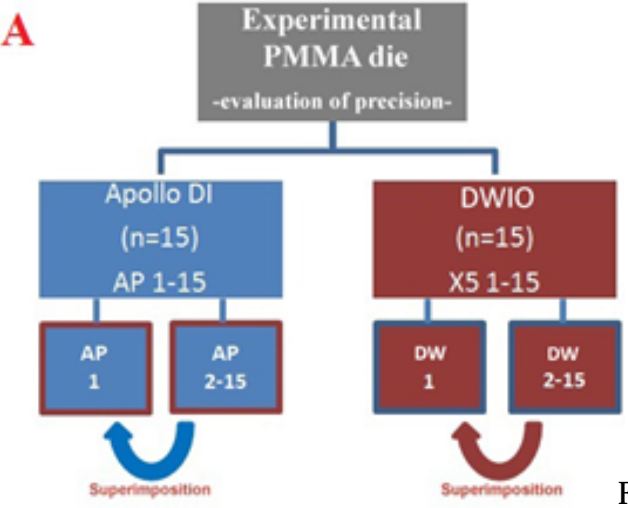

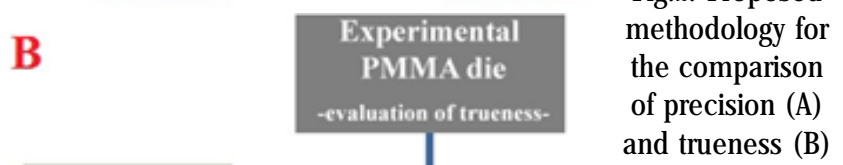

Fig.1.A. The milled PMMA stump used as the reference object; B. Parameters used for the stump preparation
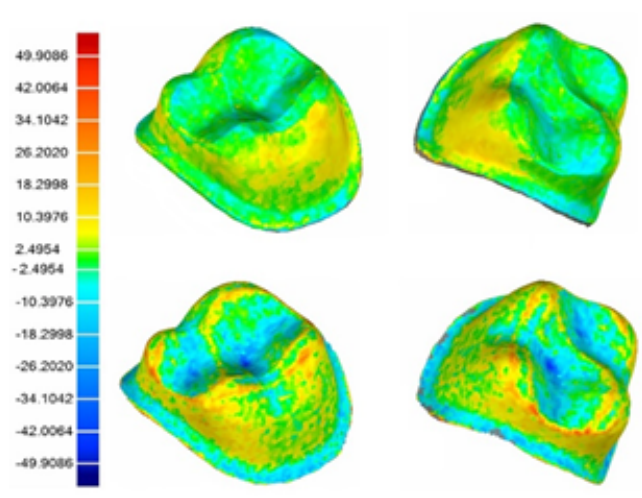
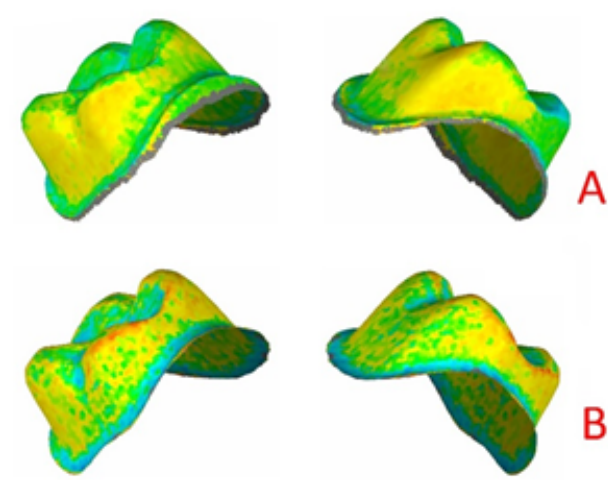

A

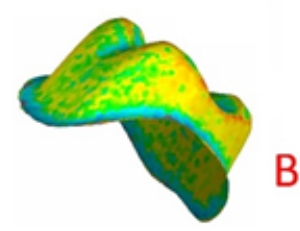

Fig. 3. Colored coded maps indicating deviation from the true value of the virtual reference model: A) DWIO, B) Apollo DI

\section{Reference scanner}

The PMMA milled stump was scanned using a XT H225 ST (Nikon Metrology Inc., Brighton, SUA) industrial CT with the purpose of obtaining the virtual reference model. For the scanning procedure, the following parameters were used: 155kV, 175 $\mu \mathrm{A}, 707 \mathrm{~ms}$ per exposure, 1500 exposures, and 2 frames per exposure, using a $0.95 \mathrm{~mm} \mathrm{Cu}$ filter and a voxel size of $16.6 \mu \mathrm{m}$. In order to reconstruct the virtual model, the Inspect $X$ software (Nikon Metrology Inc., Brighton, USA) was used and the resulting STL dataset was exported and defined as the reference value (REF) for this study.

\section{Digital comparison method}

After obtaining the digital reference model, the PMMA stump was scanned 15 times with each of the two scanners by the same operator, following the manufacturers' recommended scan indications. To determine the precision of the scanners, one randomly selected scan out of the 15 virtual models generated by a scanner was chosen as a reference and was compared to the other 14 remaining models using the best-fit superimposition algorithm of the Geomagics Qualify 2013
(Materialise, Leuven, Belgium) metrology software (fig. 2.A). In order to evaluate the trueness of the two scanners, all 15 virtual models generated by each of the two scanners were compared to the virtual reference model acquired with the industrial $\mathrm{CT}$, using the same metrology software (fig. 2.B).

The metrology software generated a color coded map of the registered deviations (fig. 3) and the Root Mean Square (RMS) error of the deviations was calculated for each performed comparison. Statistical analysis was performed with SPSS 20.0 (IBM SPSS Inc). The Levene test was used to test the homogeneity of variances and Student's t-test was used to evaluate the difference between the two groups. The level of significance was set at 0.05 .

\section{Results and discussions}

The results (mean \pm standard deviation RMS) of the measurements performed using the experimental model for trueness is $16.92 \pm 1.15 \mu \mathrm{m}$ for the DWIO scanner. By comparison, the Apollo Dl scanner was associated with a numerically bigger mean of $21.58 \pm 5.41 \mu \mathrm{m}$. To test the hypothesis that the two intraoral scanners were associated 
with statistically significant different means, an independent samples t-test was performed. The assumption of homogeneity of variances was tested and satisfied via Levene's F test, $F(28)=39.81, p=0.000$. The independent samples t-test was associated with a statistically significant effect, $t(28)=3.26, p=0.003$. Thus, the Apollo DI scanner was associated with a statistically significant smaller degree of trueness in comparison with the DWIO scanner. Cohen's d for trueness was estimated at 1.19, which is a large effect based on Cohen's guidelines.

For precision, the results of the of the measurements performed are $17.34 \pm 2.43 \mu \mathrm{m}$ for the Apollo Di scanner and $12.38 \pm 0.41 \mu \mathrm{m}$ for the DWIO scanner. To test the hypothesis that the two intraoral scanners were associated with statistically significant different means for precision, another independent samples t-test was performed. The assumption of homogeneity of variances was tested and satisfied via Levene's F test, $F(26)=11.69, p=0.002$. The independent samples t-test was associated with a statistically significant effect, $t(26)=7.62, p<0.001$. Thus, the DWIO scanner was associated with a statistically significant larger degree of precision in comparison with the Apollo DI scanner. Cohen's d for trueness was estimated at 2.88, which is a large effect based on Cohen's guidelines.

Based on the performed tests, we can state that both in terms of precision of the two scanners and their trueness, the DWIO scanner has achieved better results. This could be confirmed both visually, bythe high degree of overlapping in the comparison of scanned stumps with the reference virtual model (fig. 3), and statistically by a very low value of $p(<0.001)$ when applying the $t$ tests.

The differences in accuracies between the two tested systems might be related to different scanning technologies, as well as data processing algorithms. The different approaches of generating STL datasets from the $\mathrm{CT}$ and dental scanners, including different ways of postprocessing and filtering of the raw data, can be seen as a limitation of this study. The industrial CT was used to produce the reference dataset as it exhibits a higher accuracy than the tested intraoral scanners. As the postprocessing algorithms used by the dental scanners are not available for the researchers, the possibility to use the same algorithm for the post-processing of CT datasets was not given. As well, the generation of STL datasets from CT raw data differs a lot from the post-processing procedure after optical capturing.

Notwithstanding technological dependent errors, shaking of hands amid the scanning procedure is viewed as a common issue in the use of handheld scanners, adding artifacts and distortion of the digital impression. Although demonstrated to be technology related, several other factors, such as patient movement during scanning, using optical conditioning spray [22], as well as the presence of saliva and reflections caused by the optical proprieties of teeth, might also influence the accuracy of the scan.

Currently, numerous scientific studies performed in the field of dental scanner accuracy report in vitro and in vivo precision and trueness values for currently available intraoral and laboratory scanners. The values for trueness and precision reported in this study are situated in these limits, which range between 15-48 im for trueness and between 4-18 im for precision [23].

\section{Conclusions}

Within the limits of this study, we can state that there is a significant difference between the accuracy displayed by the two intraoral scanners tested in this study, difference that is mainly generated by the different capturing techniques used by each scanner. However, the reference object was limited in size and is equivalent to a single tooth. In clinical conditions, the scanned surface is wider; therefore a more complex topography of the reference object is required in order to allow the extrapolation of the results in clinical situations.

Acknowledgement: This work is supported by two grants of the Romanian National Authority for Scientific Research and Innovation, UEFISCDI, project number PNIII-P2-2.1-PED-2016-1907- 101PED/2017 and PNIII-P2-2.1-PED-2016-1415-142PED/2017.

\section{References}

1. AYOUB, AF., WRAY, D., MOOS, KF., J IN, J., NIBLETT, TB., URQUHART, C., Int J Adult Orthodon Orthognath Surg., 12, no. 1, 1997, p. 79.

2. KEATING, P., PARKER, RA., KEANE, D., WRIGHT, L., Br J Orthod., 113 , no. 3, 1984, p. 119.

3. NICOLA C. Materiale dentare- consideraii clinice 'i tehnice., Editura Casa Cãrii de 'tiinã, Cluj-Napoca, 2009.

4. DUKE, P., MOORE, K., HAUG, S., ANDRES, C. J Prosthet Dent., 83, no.4, 2000, p. 466.

5. MCGUINNESS, NJ ., STEPHENS, CD., Br J Orthod., 19, no. 3, 1992, p. 227.

6. KASPAROVA, MM., GRAFOVA, L., DVORAK, P., DOSTALOVA, T., PROCHAZKA, A., ELIASOVA, H., Biomed Eng Online., 12, no. 1, 2013, p. 49.

7. VAN NOORT, R., Dent Mater., 28, no. 1, 2012, 3.

8. HAZEVELD, A., HUDDLESTON SLATER, JJR., REN, Y., Am J Orthod Dentofac Orthop., 145, no.1, 2014, p. 108.

9. UZUN, G., Biotechnol Equip., 22, no. 1, p. 530.

10. DURET, F., Empriente optique., Claude Bernard University, Lyon, 1974.

11. DURET, F., BLOUIN, JL., DURET, B., J Am Dent Assoc., 117, no. 6, 1988, p. 715.

12. RICHERT, R., GOUJAT, A., VENET, L., VIGUIE, G., VIENNOT, S., ROBINSON, P., J Healthc Eng., 2017:8427595.

13. LOGOZZO, S., ZANETTI, EM., FRANCESCHINI, G., KILPELÄ, A., MÄKYNEN, A., Opt Lasers Eng., 54, no. 1, 2014, p. 203.

14. KONSTANTINOVIEE, VS., TODOROVIÆE, VS., LAZIÆE, VM., Vojnosanit Pregl., 70, no. 1, 2013, p. 80.

15. SU, T., SUN, J., J Prosthodont Res., 59, no. 4, 2015, p. 236.

16. NEDELCU, RG., PERSSON, ASK., J Prosthet Dent., 112, no. 6, 2014, p. 1461.

17. GIMENEZ, B., OZCAN, M., MARTINEZ-RUS, F., PRADIES, G., Clin Implant Dent Relat Res., Suppl 1, 2013, p. 54.

18. MANDELLI, F., GHERLONE, E., GASTALDI, G., FERRARI, M., J Prosthodont Res., 60, no. 1, 2016, p. 2.

19. GONZALEZ DE VILLAUMBROSIA, P., MARTINEZ-RUS, F., GARCIAOREJAS, A., SALIDO, MP., PRADIES, G., J Prosthet Dent., 116, no. 4, 2016, p. 543.

20. PATZELT, SBM., EMMANOUILIDI, A., STAMPF, S., STRUB, JR., ATT, W., Clin Oral Investig., 18, no.6, 2014, p. 1687.

21. RENNE, W., LUDLOW, M., FRYML, J., SCHURCH, Z., MENNITO, A., KESSLER, R., J Prosthet Dent., 118, no. 1, 2016, p. 36.

22. BURDE, A.V., DUDEA, D., CUC, S., MOLDOVAN, M., CAMPIAN, RS., Mat. Plast., 53, no. 1, 2016, p.65.

23. ENDER, A., ATTIN, T., MEHL, A., J Prosthet Dent., 115, no.3, 2016, p.313.

\footnotetext{
Manuscript received: 14.01 .2018
} 